\title{
Prion strains associated with iatrogenic CJD in French and UK human growth hormone recipients
}

\author{
Jean-Yves Douet ${ }^{1 \dagger}$, Alvina Huor ${ }^{1 \dagger}$, Hervé Cassard1', Séverine Lugan¹, Naïma Aron', Chloé Mesic ${ }^{1}$, Didier Vilette \\ Tomás Barrio ${ }^{1}$, Nathalie Streichenberger ${ }^{2,3}$, Armand Perret-Liaudet ${ }^{2,3}$, Marie-Bernadette Delisle ${ }^{4}$, Patrice Péran ${ }^{4}$, \\ Jean-Philippe Deslys ${ }^{5}$, Emmanuel Comoy ${ }^{5}$, Jean-Luc Vilotte ${ }^{6}$, Katayoun Goudarzi ${ }^{6}$, Vincent Béringue ${ }^{7}$, \\ Marcelo A. Barria ${ }^{8}$, Diane L. Ritchie ${ }^{8}$, James W. Ironside ${ }^{8}$ and Olivier Andréoletti ${ }^{1 *}$
}

\begin{abstract}
Treatment with human pituitary-derived growth hormone $(\mathrm{hGH})$ was responsible for a significant proportion of iatrogenic Creutzfeldt-Jakob disease (iCJD) cases. France and the UK experienced the largest case numbers of hGH-iCJD, with 122 and 81 cases respectively. Differences in the frequency of the three PRNP codon 129 polymorphisms (MM, $\mathrm{MV}$ and $\mathrm{VV}$ ) and the estimated incubation periods associated with each of these genotypes in the French and the UK hGH-iCJD cohorts led to the suggestion that the prion strains responsible for these two hGH-iCJD cohorts were different. In this study, we characterized the prion strains responsible for $\mathrm{hGH}-\mathrm{iCJD}$ cases originating from $\mathrm{UK}(\mathrm{n}=11)$ and France $(n=11)$ using human PrP expressing mouse models. The cases included PRNP MM, MV and VV genotypes from both countries. UK and French sporadic CJD (sCJD) cases were included as controls. The prion strains identified following inoculation with $\mathrm{hGH}$-iCJD homogenates corresponded to the two most frequently observed sCJD prion strains $\left(\mathrm{M}^{\mathrm{C}}{ }^{\mathrm{CD}}\right.$ and $\left.\mathrm{V}_{2}{ }^{\mathrm{CDD}}\right)$. However, in clear contradiction to the initial hypothesis, the prion strains that were identified in the UK and the French hGH-iCJD cases were not radically different. In the vast majority of the cases originating from both countries, the $\mathrm{V} 2^{\mathrm{CD}}$ strain or a mixture of $\mathrm{M}_{1}^{\mathrm{CD}}+\mathrm{V}^{\mathrm{CJD}}$ strains were identified. These data strongly support the contention that the differences in the epidemiological and genetic profiles observed in the UK and France hGH-iCJD cohorts cannot be attributed only to the transmission of different prion strains.
\end{abstract}

Keywords: Prion disease, latrogenic CJD, Growth hormone

\section{Introduction}

Prion diseases (otherwise known as transmissible spongiform encephalopathies) are a group of transmissible neurodegenerative disorders that occur naturally in man and a range of other mammalian species, including scrapie

\footnotetext{
*Correspondence: o.andreoletti@envt.fr

${ }^{\dagger} J$ ean-Yves Douet and Alvina Huor have contributed equally to this work 1 UMR INRAE ENVT 1225, Interactions Hôtes-Agents Pathogènes,

École Nationale Vétérinaire de Toulouse, 23 Chemin des Capelles, 31076 Toulouse, France

Full list of author information is available at the end of the article
}

in sheep and goats, and chronic wasting disease in deer and elk. Prion diseases are characterized by the accumulation of a misfolded form of the normal cellular prion protein $\left(\operatorname{PrP}^{\mathrm{C}}\right)$ in the central nervous system $(\mathrm{CNS})$ [1]. This misfolded protein (commonly referred to as $\operatorname{PrP} \mathrm{P}^{\mathrm{Sc}}$ ) is considered to be the major, if not the only, component of the transmissible agents or prions that are responsible for these diseases [2]. Serial passage of sheep scrapie in mice by intracerebral inoculation identified the presence of distinct strains of the transmissible agent based on the individual biological properties in the mice that become stable on serial passage [3]. These properties include the original author(s) and the source, provide a link to the Creative Commons licence, and indicate if changes were made. The images or other third party material in this article are included in the article's Creative Commons licence, unless indicated otherwise in a credit line to the material. If material is not included in the article's Creative Commons licence and your intended use is not permitted by statutory regulation or exceeds the permitted use, you will need to obtain permission directly from the copyright holder. To view a copy of this licence, visit http://creativecommons.org/licenses/by/4.0/. The Creative Commons Public Domain Dedication waiver (http://creativeco mmons.org/publicdomain/zero/1.0/) applies to the data made available in this article, unless otherwise stated in a credit line to the data. 
disease incubation period and neuropathological phenotype, particularly the distribution and severity of spongiform change in the brain. In the apparent absence of any nucleic acid associated with the transmissible agent, these variations in strain properties have been accounted for by conformational variability in $\mathrm{PrP}^{\mathrm{Sc}}$ that is selfpropagating [2].

Human prion diseases occur in sporadic, genetic and acquired forms. The commonest of these is the sporadic form of Creutzfeldt-Jakob disease (sCJD), which has a worldwide distribution at a remarkably consistent incidence of 1-2 cases per million population per annum. The acquired forms of human prion disease include kuru, iatrogenic Creutzfeldt-Jakob disease (iCJD) and variant Creutzfeldt-Jakob disease (vCJD) [4].

The clinicopathological phenotype of human prion diseases is variable, particularly in sCJD. One major determinant of this variability is the naturally occurring polymorphism at codon 129 in the human prion protein gene $(P R N P)$, which can encode either methionine $(\mathrm{M})$ or valine $(V)$, resulting in three possible genotypes: $M M$, MV and VV. The second major determinant is the isoform of the protease-resistant core of $\operatorname{PrP}^{\mathrm{Sc}}$ (referred to as $\operatorname{PrP}^{\text {res }}$ ) which may be detected by Western blot analysis in brain tissue from affected patients. PrP ${ }^{\text {res }}$ occurs as two major isoforms in SCJD cases that differ in the molecular weight of the unglycosylated fragments, designated Type $1(21 \mathrm{kDa})$ and Type $2(19 \mathrm{kDa})$. Distinct subtypes of SCJD have been recognized according to their clinical and neuropathological features, which largely correspond to the six possible codon 129 genotype/PrP $\mathrm{P}^{\text {res }}$ type combinations (MM1, MV1, VV1, MM2, MV2 and VV2) [5]. However, both type 1 and type $2 \operatorname{PrP}^{\text {res }}$ can be detected within either the same or different brain areas in up to $35 \%$ of sCJD patients $[6,7]$. It has been proposed that the different SCJD subtypes could result from the propagation of different strains of SCJD prions in patients. Experimental transmissions of sCJD brain homogenates to transgenic mice have demonstrated the existence of at least five strains of sCJD prions [8-13].

Although the precise relationship between prion strain diversity and the clinicopathological subtypes of SCJD remains imperfectly characterized, two strains named $\mathrm{M} 1^{\mathrm{CJD}}$ and $\mathrm{V} 2^{\mathrm{CJD}}$ seem to account for the most frequent forms of $\mathrm{SCJD}$; $\mathrm{M} 1^{\mathrm{CJD}}$ is predominantly found in the brain of MM/MV1 sCJD patients, while the $\mathrm{V} 2^{\mathrm{CJD}}$ strain is generally found in VV/MV2 sCJD patients $[8,9,11$, 14]. However, in up to $35 \%$ of sCJD patients the co-existence of both $\mathrm{M}^{\mathrm{CJD}}$ and $\mathrm{V} 2^{\mathrm{CJD}}$ strains was demonstrated by bioassay [11].

The first reported case of iatrogenic CJD (iCJD), occurring in a recipient of a corneal graft from a donor who had died from SCJD, was published in 1974 [15].
Since then, cases of iCJD have also been identified in small numbers of patients on whom neurosurgical instruments or intracerebral electrodes previously used on the brains of patients with CJD were subsequently used [16]. Larger numbers of iCJD cases (over 200 in each group) have occurred in patients inoculated with human pituitary-derived growth hormone (hGH), and in patients who received an implant of lyophilised human dura mater (hDM) during neurosurgery. Treatment of primary or secondary growth hormone deficiency in children with hGH was commenced initially in the 1950s on a small scale in a few countries. The subsequent clinical success of this treatment resulted its use on a much larger scale and in more countries. The first case of iCJD in a patient treated with hGH was reported in 1985, since when the use of hGH has ceased in many countries and replacement therapy with biosynthetic growth hormone was instigated [16].

The incidence of hGH-iCJD varies from country to country and appears to be related to the scale of the local hGH production process and the likelihood of prion contamination in the selection of autopsy cases for pituitary collection, e.g. the collection of pituitary glands from elderly patients. Since 1985 , over 240 cases of $\mathrm{iCJD}$ in hGH recipients have been reported in several countries, with the largest numbers of cases occurring in France and the United Kingdom (UK). Four cases of $\mathrm{iCJD}$ in human pituitary gonadotrophin recipients have also occurred, all in Australia; one of these patients died in the UK [16].

Overall, 1849 patients from the UK and Ireland were treated with hGH produced in the UK from 1959 until 1985. Since 1985, 81 deaths from iCJD have occurred in this cohort. It has been established that one particular preparation of UK pituitary-derived hGH (the Hartree-modified Wilhelmi (HWP) preparation) had been administered to all hGH recipients who had developed iCJD, albeit from different batches, in varying quantities and over different time periods [17]. In France, 122 cases of iCJD in $1443 \mathrm{hGH}$ recipients have occurred between 1991 and 2019. All were treated between December 1983 and July 1985, which has been identified as a high- risk period for hGH-iCJD in France $[18,19]$.

Deaths from hGH-iCJD continue to occur in France and in the UK, with the most recent death occurring in 2019 and 2020 respectively, 35 years since hGH therapy ceased in these countries. A precise calculation of incubation periods in human pituitary hormone recipients is difficult, since the patients are often treated over a period of years; the time period from the mid-point of pituitary hormone treatment to the onset of clinical symptoms of iCJD is therefore used as an estimate for the incubation period. 
A major factor influencing incubation periods in hGHiCJD is the PRNP codon 129 polymorphism of the recipient. It has long been recognized that homozygosity at this locus may predispose to both $\mathrm{iCJD}$ and sporadic CJD (sCJD) [20]. In the healthy UK and French populations, the distribution of the individual genotypes at codon 129 of the PRNP gene is similar at around $40 \% \mathrm{MM}, 10 \% \mathrm{VV}$ and $50 \%$ MV [16, 21].

Variations in the frequency of the three PRNP codon 129 polymorphisms (MM, MV and VV) and estimated incubation periods associated with each of these three genotypes have been reported in hGH-iCJD cohorts in different countries [16].

In France, the mean incubation period for hGH-iCJD has been estimated at 14.2 years. However, incubation periods differed according to the patient's age at start of treatment, with the shortest incubation periods observed in the group of patients aged between 10 and 13.7 years when treatment started. Incubation periods were also influenced by the patient's PRNP codon 129 genotype, with mean values of 12.6 years in MM and VV homozygotes and 17.6 years in MV heterozygotes [18].

The risk of developing $\mathrm{iCJD}$ in the UK hGH recipients was greatest in those patients who started treatment at ages 8-10 years [17]. Estimated incubation periods in the UK hGH-iCJD patients range from 7 to 40 years; these prolonged incubation periods are reminiscent of those occurring in kuru, where incubation periods of over 40 years have been reported [22]. The incubation periods in the UK hGH-iCJD patients are also influenced by the patient's PRNP codon 129 genotype, but in contrast to the French patients, UK VV homozygous patients had a mean incubation period of 14.3 years, while in MV heterozygous patients the mean incubation period was 23.4 years. The longest incubation periods in UK patients occurred in codon 129 MM homozygotes (mean value 30.8 years) [22].

These observations raised the hypothesis that different prion strains (most likely originating from undetected cases of SCJD in the donor population) contaminated the hGH preparations administered to recipients in the UK and in France, resulting in different incubation periods for each of the PRNP codon 129 subgroups between these countries $[16,23]$. This study aims to test this hypothesis by performing experimental transmissions of $22 \mathrm{hGH}-\mathrm{iCJD}$ brain homogenates from patients with all three codon 129 genotypes from France (11 cases) and the UK (11 cases) into a panel of well characterized human-PrP-expressing transgenic mice (tgHu), following an established methodology that has been used extensively to identify SCJD prion strains in a range of tissue samples from France, the UK and Spain [11, 14]. Sporadic CJD cases originating from France and the UK were also used as controls in this study. This is the first study, to our knowledge, where the strain characteristics of prions in $\mathrm{hGH}-\mathrm{iCJD}$ cases have been defined and compared to sCJD prion strains.

In clear contradiction to the initial hypothesis, the prion strains that were identified in the UK and the French hGH-iCJD cases were not radically different. In the vast majority of the cases originating from both countries, the $\mathrm{V} 2^{\mathrm{CJD}}$ strain or a mixture of $\mathrm{M} 1{ }^{\mathrm{CJD}}+\mathrm{V} 2^{\mathrm{CJD}}$ strains were identified by the strain typing in tgHu. These data strongly support the contention that differences observed in the epidemiological profiles between hGHiCJD cases in the UK and France cannot be attributed solely to the transmission of different prion strains.

\section{Materials and methods}

\section{Ethical statement}

All animal experiments were performed in compliance with institutional and French national guidelines in accordance with the European Union Directives 86/609/ EEC and 2010/63/EU. Experiments were approved by the Committee on the Ethics of Animal Experiments of the author's institutions: INRA Toulouse/ENVT (Permit Number: 01734.01).

Concerning the human CJD samples, in all cases informed consent for research was obtained and the material used had appropriate ethical approval for use in this project.

France: human brain samples were obtained from the Brain Bank of CHU of Toulouse, Cardiobiotec (Centre de Resources Biologiques des Hospices Civils de Lyon) and former French national reference laboratory (CEA, Fontenay aux roses) under approval number AC62009973/20-01-2010. Samples were pseudo-anonymized before dispatch.

UK: Human brain samples were obtained from the National CJD Research and Surveillance Unit Brain and Tissue Bank in Edinburgh, UK, which is part of the MRC Edinburgh Brain Bank. For the purposes of this study, samples were pseudo-anonymized using a Brain Bank reference number. All UK cases had informed consent for research and their supply and use in this study was covered by Ethics Approval (LREC 2000/4/157: National Creutzfeldt-Jakob disease tissue bank: acquisition and use of autopsy material for research on human transmissible spongiform encephalopathies, Professor James Ironside, amended date: 9th October 2007).

\section{hGH-iCJD cases}

22 cases of hGH-iCJD, each of which had frozen tissue (200 to $500 \mathrm{mg}$ ) available (cerebral cortex or cerebellar cortex), were included in this study. The patients originated from France and the UK. A diagnosis of iatrogenic 
CJD was made in each case according to established international criteria (ECDC 2021: https://www.ecdc. europa.eu/en/infectious-diseases-public-health/variantcreutzfeldt-jakob-disease/eu-case-definition). The UK cases are part of a larger series of UK hGH-iCJD cases that has been extensively characterised in terms of neuropathological features, $\mathrm{PrP}^{\text {res }}$ profiles and prion protein amplification properties [24]. None of the patients had a familial history of prion disease and, in each case, the entire PRNP coding sequence was analysed [25, 26]. For each patient the age at death and the estimated incubation period (based on individual hGH treatment histories) are indicated (Table 1).

\section{Tissue homogenate preparation}

For each hGH-iCJD case, $175 \pm 20 \mathrm{mg}$ of frozen brain tissue was homogenized in $5 \%$ glucose in distilled water in grinding tubes (Bio-Rad) adjusted to $10 \%(\mathrm{w} / \mathrm{v})$ using a $\mathrm{TeSeE}{ }^{\mathrm{TM}}$ Process $48^{\mathrm{TM}}$ homogenizer (Bio-Rad).

\section{Transgenic mouse lines}

$\operatorname{Tg} 340$ and tg361 mouse lines that express human $\operatorname{PrP}$ methionine at codon 129 or valine at codon 129 , respectively, in a prion protein gene knockout $\left(\mathrm{PrP}^{\mathrm{Ko}}\right)$ background, were generated as previously described $[9,27]$. Both tg340 (tgMet) and tg361 (tgVal) are homozygous for human PRNP gene.

\section{Mouse bioassays}

Six- to ten-week-old female mice were anesthetized and inoculated with $2 \mathrm{mg}$ of brain equivalent $(20 \mu \mathrm{L}$ of a $10 \%$ cerebral or cerebellar cortex homogenate) in the right parietal lobe using a 25-gauge disposable hypodermic needle.

Mice were observed daily and their neurological status was assessed weekly by qualified veterinarians. Three signs of neurological dysfunction (tremor, ataxia, difficulty righting from supine position, rigidity of tail, kyphosis, paralysis of the lower limbs or bradykinesia,) were necessary to score a mouse positive for prion disease [28].

When clinically progressive TSE disease was evident, the animals were euthanized and their brains harvested. Half of the brain from those animals that had displayed TSE clinical signs was fixed by immersion in $10 \%$ formol saline and the other half was frozen at $-20{ }^{\circ} \mathrm{C}$. Tissues from animals found dead were frozen (no formalin fixation). Incubation period was expressed as the mean of the survival (time to death) days post inoculation (dpi) of all the symptomatic mice scored positive for $\operatorname{Pr} \mathrm{P}^{\text {res }}$, with its corresponding standard deviation.

\section{Abnormal PrP western blot (WB) detection}

PK resistant abnormal PrP extraction $\left(\mathrm{PrP}^{\mathrm{res}}\right)$ and Western blot were performed as previously described [29]. Immunodetection was performed using monoclonal PrPspecific antibodie Sha31 $(1 \mu \mathrm{g} / \mathrm{ml})$, which recognize the amino acid sequence YEDRYYRE (145-152) [30].

\section{Vacuolar lesion profiles}

Hematoxylin-Eosin-stained paraffin-embedded brain tissue sections were used to establish standardized vacuolar lesion profiles in mice as previously described [3,31]. Each lesion profile was based on data obtained from 4 to 6 animals.

\section{Reference M1 and V2 CJD strains}

Successive $1 / 10$ dilutions of $10 \%$ brain homogenate (frontal cortex) from a SCJD MM1 and a SCJD VV2) case were inoculated intra-cerebrally to tgMet $(n=6)$ and tgVal $(\mathrm{n}=6)$. These data were already presented in a previous study [32] as cases 1 and 6, respectively. The brain of the last $\mathrm{PrP}^{\mathrm{Sc}}$ positive MM1 in tgMet and VV2 in tgVal mice (in highest dilution groups) were used to re-inoculate groups of tgMet $(n=12)$ and tgVal $(n=12)$. The brain of these tgMet and TgVal animals were pooled to constitute two stocks of reference material (named M1 CJD and $\mathrm{V} 2^{\mathrm{CJD}}$ ). The $\mathrm{V} 2^{\mathrm{CJD}}$ stock homogenate was end point titrated by bioassay in tgVal (inoculation of successive $1 / 10$ dilutions of $10 \%$ homogenates-Additional file 1 : Table S1).

\section{Data availability}

The authors confirm that the data supporting the findings of this study are available within the article and its supplementary material.

\section{Results}

$22 \mathrm{hGH}$-iCJD cases were selected, which originated either from France $(n=11)$ or the UK $(n=11)$ and included all three possible PRNP genotypes at codon 129 (Homozygous $\mathrm{Met}_{129}$ or $\mathrm{Val}_{129}$, Heterozygous $\mathrm{Met}_{129} /$ $\mathrm{Val}_{129}$ ) (Table 1). In both the UK and France, the availability of hGH-iCJD cases from certain PRNP genotypes (such as MM in the UK or VV in France) with suitable biological (frozen) material was limited. Information on the selected 22 cases, including the estimated incubation period of the disease is included in Table 1.

From the frozen material available, tissue homogenates (10\% weight volume) corresponding to either cerebral (frontal, parietal or temporal) cortex or cerebellar cortex from each hGH-iCJD case were transmitted (two iterative passages) to mice homozygous for either methionine (tgMet) or valine (tgVal) at codon 129 of human 
Table 1 Transmission of tissue isolates (10\% cerebral/cerebellar cortex homogenates from hGH-iCJD cases) into mice expressing the human PrP (methionine, valine, at codon 129)

\begin{tabular}{|c|c|c|c|c|c|c|c|c|c|c|c|}
\hline \multirow{2}{*}{\multicolumn{2}{|c|}{ Isolate number }} & \multicolumn{8}{|c|}{ Cases } & & \multirow[t]{2}{*}{ Brain area } \\
\hline & & \multicolumn{3}{|c|}{ Codon 129} & Origin & Year & \multicolumn{2}{|c|}{ Age } & Incub period & & \\
\hline \multicolumn{2}{|l|}{1} & \multicolumn{2}{|l|}{$\mathrm{MM}$} & \multicolumn{2}{|l|}{$\mathrm{Fr}$} & 2001 & \multicolumn{2}{|l|}{31} & 16 & \multicolumn{2}{|c|}{ Cort } \\
\hline \multicolumn{4}{|l|}{2} & \multicolumn{2}{|l|}{$\mathrm{Fr}$} & 2006 & \multicolumn{2}{|l|}{39} & 21 & \multicolumn{2}{|c|}{ Cort } \\
\hline \multicolumn{4}{|l|}{3} & \multicolumn{2}{|l|}{$\mathrm{Fr}$} & 2006 & 36 & 23 & & & Cort \\
\hline 4 & & & & $\mathrm{Fr}$ & & 2003 & 33 & 20 & & & Cereb \\
\hline 5 & & & & $\mathrm{Fr}$ & & 2004 & 35 & 21 & & & Cort \\
\hline 6 & & & & UK & & 2011 & 46 & 29 & & & Cort \\
\hline 7 & & & & UK & & 2012 & 42 & 32 & & & Cort \\
\hline 8 & & MV & & UK & & 2001 & 30 & 20 & & & Cort \\
\hline 9 & & & & UK & & 1999 & 37 & 19 & & & Cort \\
\hline 10 & & & & $\mathrm{Fr}$ & & 2006 & 38 & 25 & & & Cort \\
\hline 11 & & & & $\mathrm{Fr}$ & & 2008 & 27 & 24 & & & Cereb \\
\hline 12 & & & & $\mathrm{Fr}$ & & 2003 & 35 & 23 & & & Cereb \\
\hline 13 & & & & UK & & 1990 & 34 & 17 & & & Cort \\
\hline 14 & & W & & UK & & 1998 & 27 & 16 & & & Cort \\
\hline 15 & & & & UK & & 1997 & 36 & 19 & & & Cort \\
\hline 16 & & & & UK & & 1995 & 33 & 18 & & & Cort \\
\hline 17 & & & & UK & & 1994 & 25 & 11 & & & Cort \\
\hline 18 & & & & $\mathrm{Fr}$ & & 1991 & 11 & 5 & & & Cort \\
\hline 19 & & & & $\mathrm{Fr}$ & & 2000 & 27 & 16 & & & Cort \\
\hline 20 & & & & UK & & 1993 & 30 & 13 & & & Cort \\
\hline 21 & & & & UK & & 1992 & 31 & 16 & & & Cort \\
\hline 22 & & & & $\mathrm{Fr}$ & & 1999 & 24 & 15 & & & Cort \\
\hline Isolate & TgM & & & & & & & TgVal $_{129}$ & & & \\
\hline & Pass & & & Passage 2 & & Passage3 & & Passage 1 & & Passage 2 & \\
\hline & $\begin{array}{l}\text { Surv } \\
\text { (mea }\end{array}$ & & PrPres & $\begin{array}{l}\text { Survival time } \\
(\text { mean } \pm \text { SD) }\end{array}$ & PrPres & $\begin{array}{l}\text { Survival time } \\
(\text { mean } \pm S D)\end{array}$ & PrPres & $\begin{array}{l}\text { Survival time } \\
(\text { mean } \pm S D)\end{array}$ & PrPres & $\begin{array}{l}\text { Survival time } \\
(\text { mean } \pm \text { SD) }\end{array}$ & Prpres \\
\hline 1 & $585=$ & & 1 & $487 \pm 34$ & 1 & ND & & $173 \pm 3$ & 2 & $171 \pm 2$ & 2 \\
\hline 2 & $582=$ & & 1 & $492 \pm 57$ & 1 & ND & & $162 \pm 3$ & 2 & $179 \pm 7$ & 2 \\
\hline 3 & $569=$ & & 1 & $>400^{*}$ & & & & $163 \pm 7$ & 2 & $181 \pm 11$ & 2 \\
\hline 4 & $593=$ & & 1 & $298 \pm 61$ & 1 & $206 \pm 9$ & 1 & $195 \pm 13$ & 2 & $165 \pm 3$ & 2 \\
\hline 5 & $453=$ & & 1 & $204 \pm 4$ & 1 & ND & & $180 \pm 6$ & 2 & $174 \pm 9$ & 2 \\
\hline 6 & $246=$ & & 1 & $213 \pm 10$ & 1 & ND & & $206 \pm 6$ & 2 & $161 \pm 3$ & 2 \\
\hline 7 & 230 & & 1 & $193 \pm 6$ & 1 & ND & & $313 \pm 5$ & 1 & $271 \pm 5$ & 1 \\
\hline 8 & $562=$ & & 1 & $456 \pm 6$ & 1 & ND & & $211 \pm 12$ & 2 & $173 \pm 7$ & 2 \\
\hline 9 & $635=$ & & 1 & $503 \pm 19$ & 1 & ND & & $172 \pm 10$ & 2 & $177 \pm 7$ & 2 \\
\hline 10 & $525=$ & & 1 & $488 \pm 31$ & 1 & ND & & $188 \pm 15$ & 2 & $169 \pm 10$ & 2 \\
\hline 11 & $511=$ & & 1 & $>400^{*}$ & 1 & ND & & $164 \pm 5$ & 2 & $166 \pm 9$ & 2 \\
\hline 12 & $566=$ & & 1 & $299 \pm 42$ & 1 & $194 \pm 4$ & 1 & $160 \pm 10$ & 2 & $163 \pm 4$ & 2 \\
\hline 13 & $337=$ & & 1 & $212 \pm 13$ & 1 & ND & & $193 \pm 5$ & 2 & $176 \pm 15$ & 2 \\
\hline 14 & $626=$ & & 1 & $613 \pm 21$ & 1 & ND & & $176 \pm 9$ & 2 & ND & 2 \\
\hline 15 & $423=$ & & 1 & $669 \pm 56$ & 1 & ND & & $180 \pm 9$ & 2 & $175 \pm 5$ & 2 \\
\hline 16 & $665=$ & & 1 & $484 \pm 30$ & 1 & ND & & $165 \pm 5$ & 2 & $175 \pm 14$ & 2 \\
\hline 17 & $628=$ & & 1 & $568 \pm 82$ & 1 & ND & & $198 \pm 7$ & 2 & $169 \pm 7$ & 2 \\
\hline 18 & $565=$ & & 1 & $>400^{*}$ & 1 & & & $165 \pm 5$ & 2 & $180 \pm 10$ & 2 \\
\hline 19 & $759=$ & & 1 & $>400^{*}$ & 1 & & & $171 \pm 7$ & 2 & $177 \pm 8$ & 2 \\
\hline 20 & $612=$ & & 1 & $312 \pm 49$ & 1 & $202 \pm 4$ & 1 & $178 \pm 7$ & 2 & $180 \pm 7$ & 2 \\
\hline
\end{tabular}


Table 1 (continued)

\begin{tabular}{|c|c|c|c|c|c|c|c|c|c|c|}
\hline \multirow{3}{*}{$\begin{array}{l}\text { Isolate } \\
\text { number }\end{array}$} & \multicolumn{6}{|l|}{ TgMet $_{129}$} & \multicolumn{4}{|l|}{ TgVal $_{129}$} \\
\hline & \multicolumn{2}{|l|}{ Passage 1} & \multicolumn{2}{|l|}{ Passage 2} & \multicolumn{2}{|l|}{ Passage3 } & \multicolumn{2}{|l|}{ Passage 1} & \multicolumn{2}{|l|}{ Passage 2} \\
\hline & $\begin{array}{l}\text { Survival time } \\
(\text { mean } \pm \text { SD) }\end{array}$ & PrPres & $\begin{array}{l}\text { Survival time } \\
(\text { mean } \pm S D)\end{array}$ & PrPres & $\begin{array}{l}\text { Survival time } \\
(\text { mean } \pm S D)\end{array}$ & PrPres & $\begin{array}{l}\text { Survival time } \\
(\text { mean } \pm \text { SD) }\end{array}$ & PrPres & $\begin{array}{l}\text { Survival time } \\
(\text { mean } \pm \text { SD) }\end{array}$ & Prpres \\
\hline 21 & $446 \pm 165$ & 1 & $210 \pm 12$ & 1 & ND & & $194 \pm 7$ & 2 & $170 \pm 3$ & 2 \\
\hline 22 & $362 \pm 48$ & 1 & $229 \pm 8$ & 1 & ND & & $439^{* *}$ & 1 & ND & \\
\hline
\end{tabular}

Transgenic mice that express the Met $_{129}$ (tgMet), Val $_{129}$ (tgVal) human PrP were inoculated intra-cerebrally (20 $\mu \mathrm{L}$ per mouse) with human growth hormone (hGH) iatrogenic Creutzfeldt-Jakob brain tissue homogenates (frontal, temporal or parietal cortex: (cort) or cerebrellar cortex: (cereb)) from patients originating (orig.)

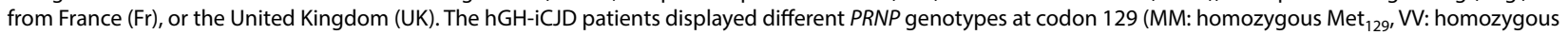
$\mathrm{Val}_{129}, \mathrm{MV}$ : heterozygous Met/Val ${ }_{129}$ ). For each patient, the country of origin, the year of death and age in years at death are indicated. The estimated duration of the incubation period in years (based on the hGH treatment history) is also indicated. After the first and second passages, brain tissue from the clinically affected mice were pooled and used for a next passage in the same line. The PrPres WB isoforms (type 1 or type 2) identified in mouse brains are reported for each two passages. Survival times are shown as mean \pm standard deviation (SD). $100 \%$ attack rate transmission were observed in all cases

ND not done

*Transmission still ongoing with no dead animals observed at the reported date

${ }^{* *}$ A single inoculated animal was positive

$\operatorname{PrP}$ (Table 1). These two tgHu PrP mouse lines have been shown to express approximately fourfold more $\operatorname{PrP}^{\mathrm{C}}$ in their brain than human brain tissue [9].

In parallel, French $(n=7)$ and UK $(n=4)$ cases of sCJD, classified as MM1, MV1, MV2 and VV2, were transmitted to tgMet and TgVal. (Table 2). Data from these sCJD transmissions have been previously reported in a recent study that aimed to type the prion strains in the brain of MM/MV1 and VV/MV2 sCJD affected patients [11]. Based on the transmission properties of incubation period, lesion profile and biological cloning of prion component present in different brain isolates, this study allowed the identification of two SCJD strains, named as $\mathrm{M} 1^{\mathrm{CID}}$ and $\mathrm{V} 2^{\mathrm{CJD}}$, that could be present as either pure components or as a mixture in the sCJD isolates (Table 2).

In the French and UK hGH-iCJD isolates, three distinct transmission patterns were observed in mice inoculated with the panel of tissue homogenates.

The first and most frequent transmission pattern $(\mathrm{n}=13$ cases), was observed in French MM $(\mathrm{n}=3$, cases $1-3), M V(n=2$, cases 10,11$)$ and $V V(n=2$, cases 18,19$)$; and UK MV $(\mathrm{n}=2$, cases 8,9$), \mathrm{VV}(\mathrm{n}=4$, cases 14-17) hGH-iCJD patients. It was characterized by a short incubation period in tgVal ( 160 to $180 \mathrm{dpi}$ ) and a long incubation period in tgMet ( 400 to $700 \mathrm{dpi}$ ) (Table 1, Fig. 1 ). All tgMet mice accumulated a type $1 \mathrm{PrP}^{\text {res }}$ in their brain, while type $2 \mathrm{PrP}^{\text {res }}$ was observed in the brain collected from tgVal mice (Table 1, Fig. 2).

This pattern was very similar to that observed in tgMet and tgVal inoculated with the $\mathrm{V} 2{ }^{\mathrm{CJD}}$ strain (Table 3, Fig. 1) which was observed in the brain of some French and UK MV2 and VV2 sCJD-affected patients (cases 30-32) (Table 2). The vacuolar lesion profile in the brain of the mice (after second passage) confirmed the propagation of the $\mathrm{V} 2^{\mathrm{CJD}}$ prion strain in both the tgMet and tgVal that had been inoculated with these $13 \mathrm{hGH}-\mathrm{iCJD}$ cases (Fig. 3).

The second transmission pattern observed was observed in one MM UK hGH-iCJD case (case 7). It was characterized by a short incubation period in tgMet ( $200 \mathrm{dpi})$, and a longer one in tgVal ( $300 \mathrm{dpi})$ (Table 1 , Fig. 1). Irrespective of the inoculated mouse line, a type $1 \mathrm{PrP}^{\text {res }}$ was observed in the brain of the inoculated animals (Table 1, Fig. 1). These features were similar to those associated with the transmission of the $\mathrm{M}^{\mathrm{CJD}}$ strain (Table 3) which could be observed in French and UK MM1 and in a part of the MV1 sCJD affected patients (cases 23-26) (Table 2). The vacuolar lesion profile in the brain of the inoculated mice (after second passage) confirmed the propagation of $\mathrm{M} 1{ }^{\mathrm{CJD}}$ prion strain in tgMet and tgVal inoculated with hGH-iCJD case 7.

In another case (case 22, French origin, VV genotype), available transmission results and lesion profiles in tgMet and tgVal, were also compatible with the presence of $\mathrm{M} 1^{\mathrm{CJD}}$ strain. However, incomplete second passage of this isolate in tgVal at the time of writing precluded drawing a definitive conclusion on the nature of the prion strain.

A third transmission profile was identified in French MM $(\mathrm{n}=2$, cases 4,5$)$ and $M V(n=1$, case 12$)$ cases as well as in UK MM $(n=1$, case 6$), M V(n=1$, case 13$)$ and $\mathrm{VV}(\mathrm{n}=2$, cases 20,21$)$ patients.

This transmission pattern was characterized on second passage by a short incubation period in tgMet $(\sim 200-300$ $\mathrm{dpi}$ ), and a short incubation period in tgVal (about 160200 dpi) (Table 1, Fig. 1). A type $1 \mathrm{PrP}^{\text {res }}$ accumulated in the brain of tgMet while type $2 \mathrm{PrP}^{\text {res }}$ was observed in tgVal mice (Fig. 2). In these isolates, the vacuolar lesion 


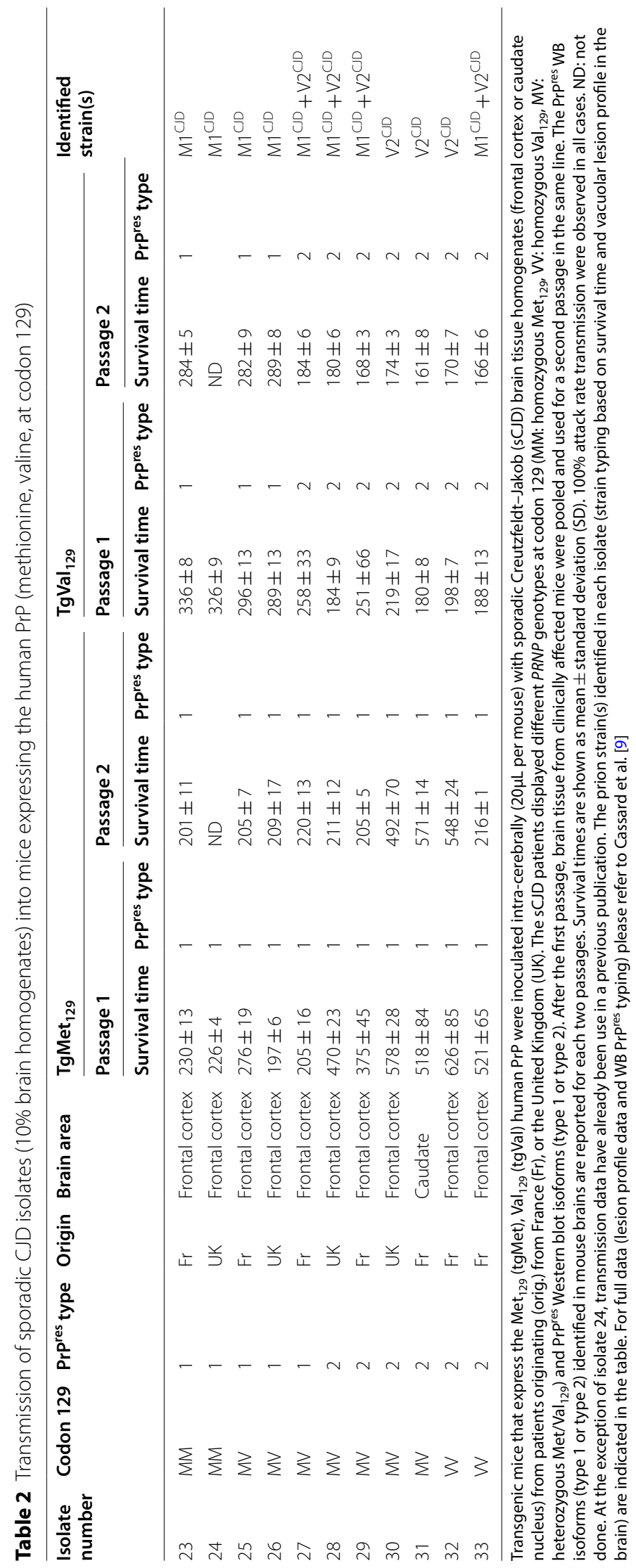


Passage 1
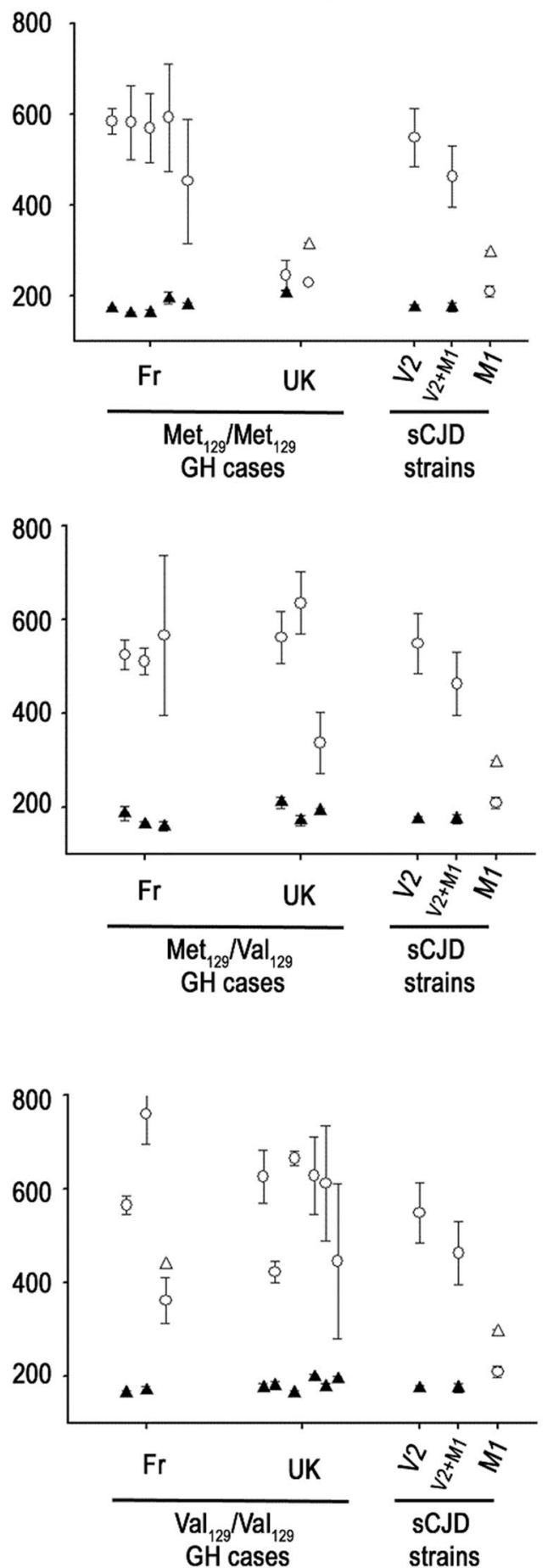

Passage 2
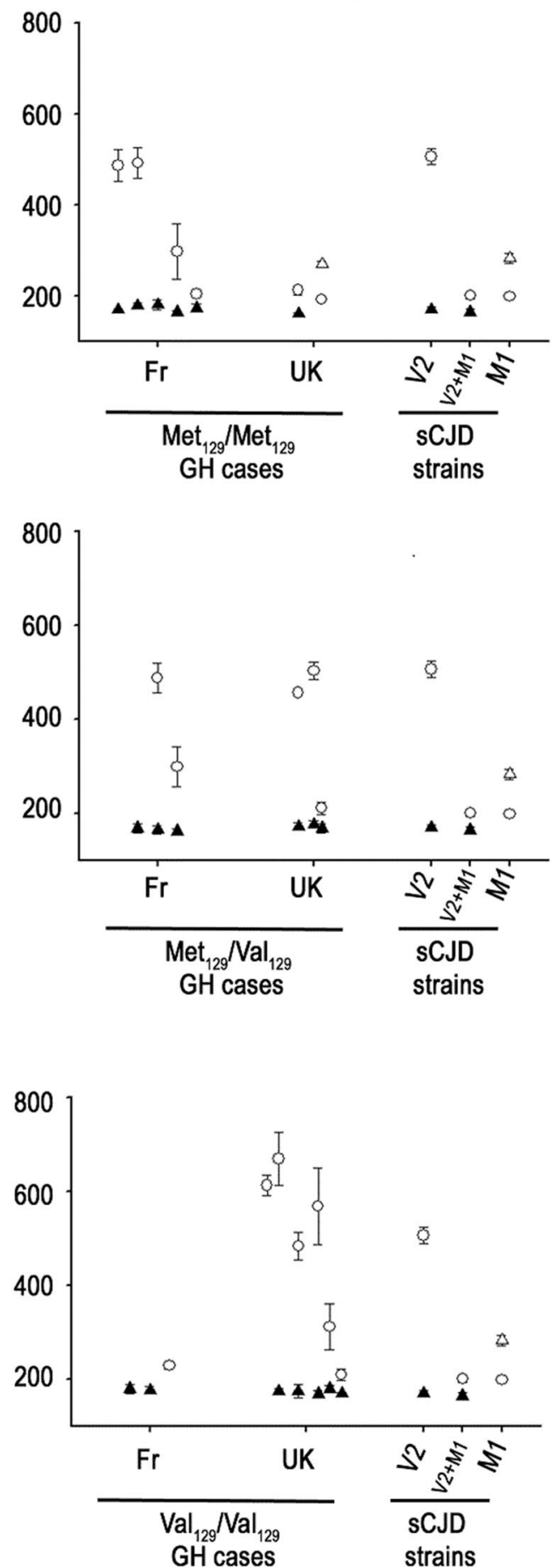

Fig. 1 Survival times of human PrP-expressing mice (tgHu) inoculated with growth hormone CJD cases originating from France and UK. Transgenic mice that express the $\mathrm{Met}_{129}$ (tgMet), $\mathrm{Val}_{129}$ (tgVal) human PrP were inoculated intra-cerebrally (6 mice, 20 $\mathrm{\mu L}$ per mouse) with a 10\% brain homogenate from hGH-iCJD cases of French and UK origin. Two iterative passages were performed in each mouse line (Table 1). For each passage, results are presented according to the country of origin (Fr and UK) and the PRNP codon 129 genotype of patients (homozygous Met129: MMheterozygous Met129/Nal129: MV—homozygous Val129: V). Survival time (mean \pm SD in days post inoculation) in tg Met (O) and tg Val ( $\Delta$ ). White/ black symbols correspond to a type 1/type 2 PrPres (as assessed by Western blot) in the brain of the mice respectively. Survival times in tgMet and TgVal associated with $\mathrm{M}_{1}^{\mathrm{CD}}$ and $\mathrm{V}_{2}^{\mathrm{CD}}$ cloned strains as well as an artificial mixture of $\mathrm{V}_{2}^{\mathrm{CD}}+\mathrm{M}_{1}^{\mathrm{CD}}\left(10^{-4}\right.$ diluted) are included as reference (see Table 2) 


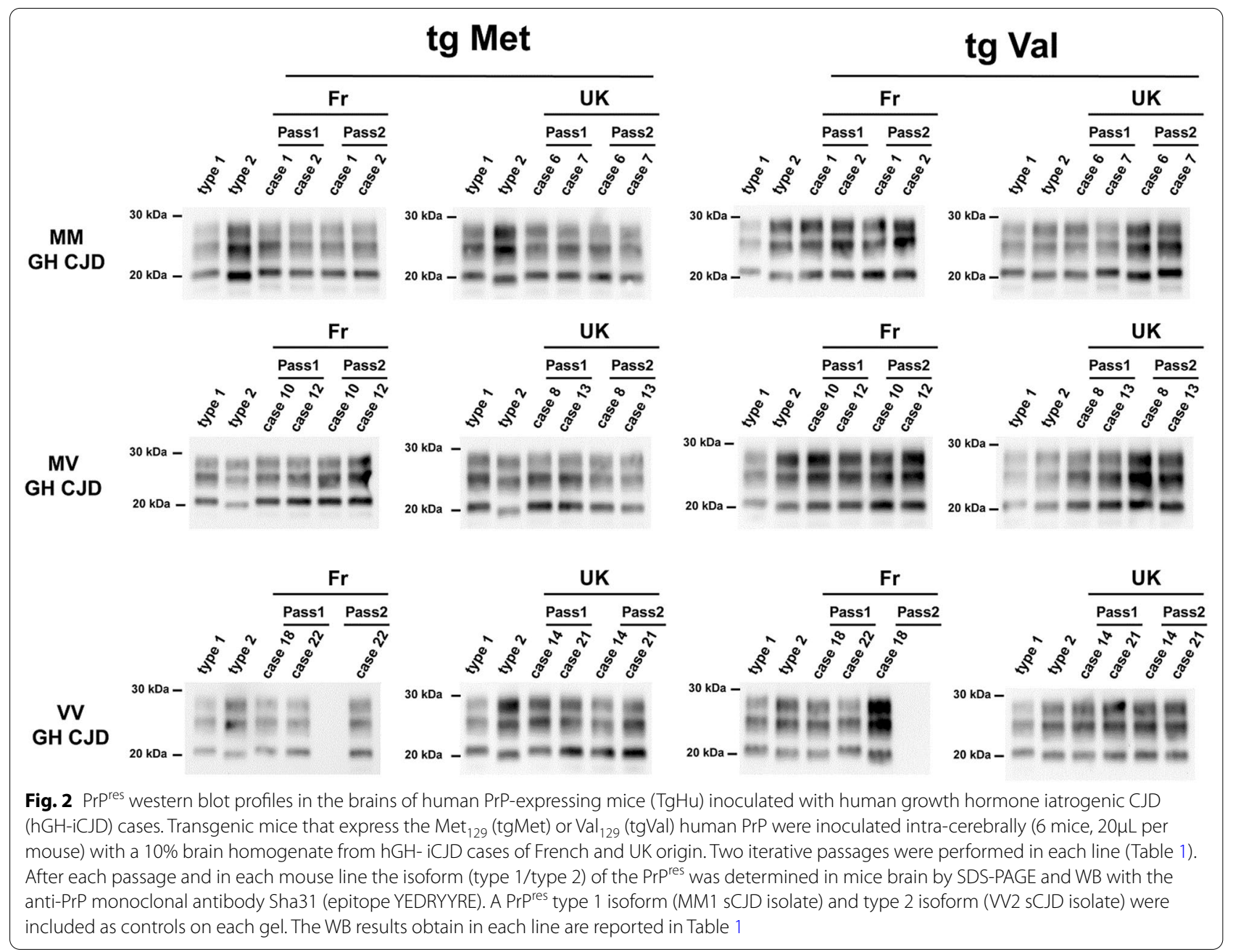

profiles in the TgMet matched with the profiles observed in mice inoculated with $\mathrm{M}^{\mathrm{CID}}$ strain while in the tgVal mice it corresponded to the $\mathrm{V} 2^{\mathrm{CJD}}$ strain (Fig. 3). Strikingly, the transmission of artificial mixtures containing $\mathrm{V} 2^{\mathrm{CJD}}$ cloned strain and a low dilution $\left(10^{-3}\right.$ to $\left.10^{-4}\right)$ of the $\mathrm{M} 1^{\mathrm{CJD}}$ cloned strain in tgMet and $\mathrm{TgVal}$ mice resulted in similar transmission patterns (Table 3, Fig. 3).

\section{Discussion}

\section{Representativeness of the panel of hGH-iCJD cases}

hGH-iCJD cases are considered to be the consequence of childhood treatment with human growth hormone, prepared using pituitary glands collected from donors that were either affected with or at a late stage of incubation of sCJD. France $(n=122)$ and the UK $(n=81)$ account for the largest numbers of hGH-iCJD patients identified worldwide. The epidemiological profile of the hGHiCJD cases in these countries differs in the distribution of PRNP genotypes at codon 129 and in the mean incubation period in each genotype group. These differences between the UK and France have been proposed to have resulted from contamination with different prion strains $[16,23,24]$.

Bioassays in reporter animal models, followed by the phenotyping of the propagated prions (vacuolar lesion profile in the brain and incubation period) remains the gold standard approach for the characterization of prion strains. Over the last decade, transgenic mice that express different human PrP variants at codon $129(\operatorname{tgHu})$ have been shown to be valuable models in which to discriminate between different human prion agents and have provided valuable insights in the diversity of the prion strains responsible for sCJD [8-13]. These mouse models have allowed the identification of five different prion strains associated with SCJD among which two, named $\mathrm{M} 1^{\mathrm{CID}}$ and $\mathrm{V} 2^{\mathrm{CID}}$, are thought responsible for the most frequent clinico-pathological forms of sCJD (observed in MM/MV1 and VV/MV2 patients, respectively) [8-11]. These same animal models also demonstrated that in around $30 \%$ of the MV1, 


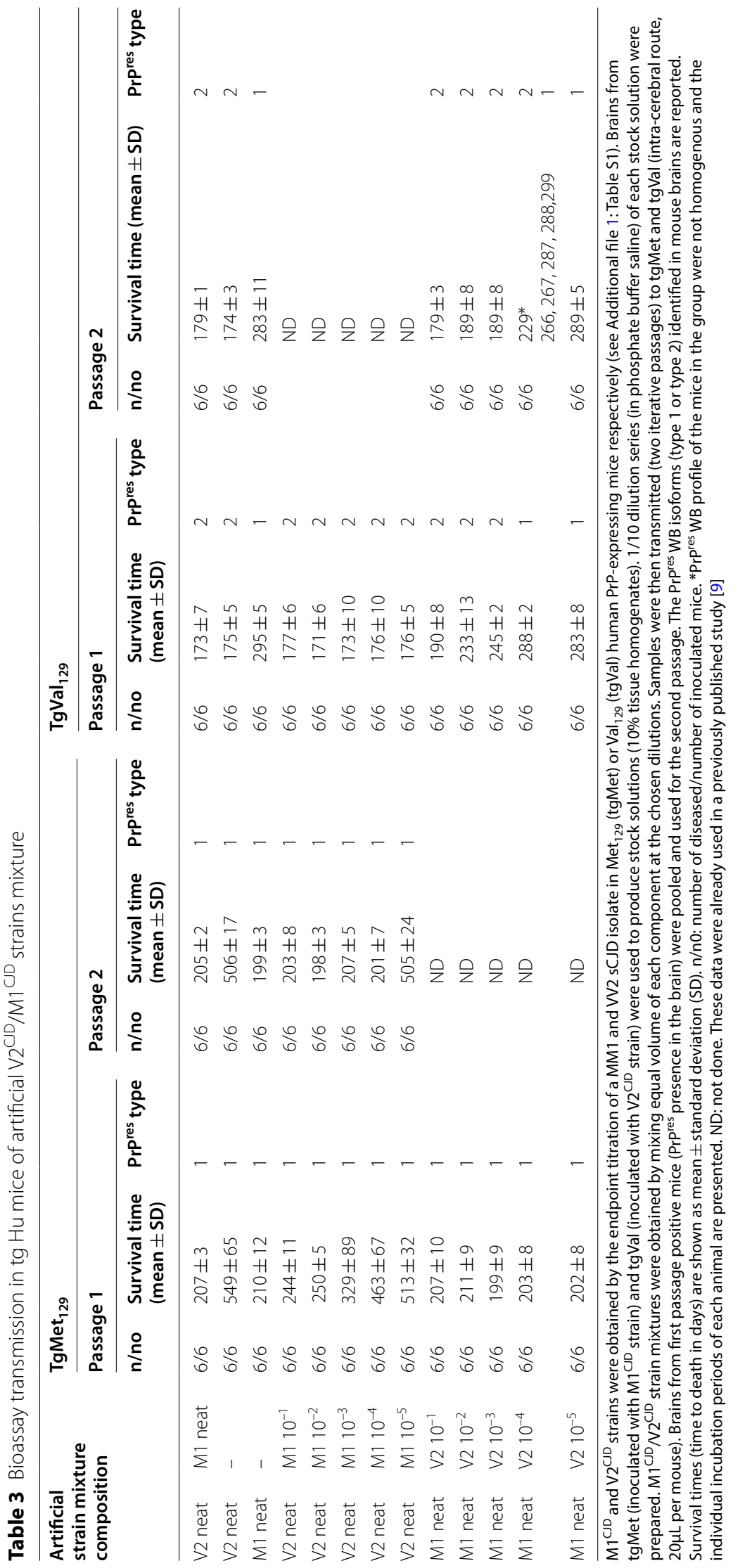


Tg Met

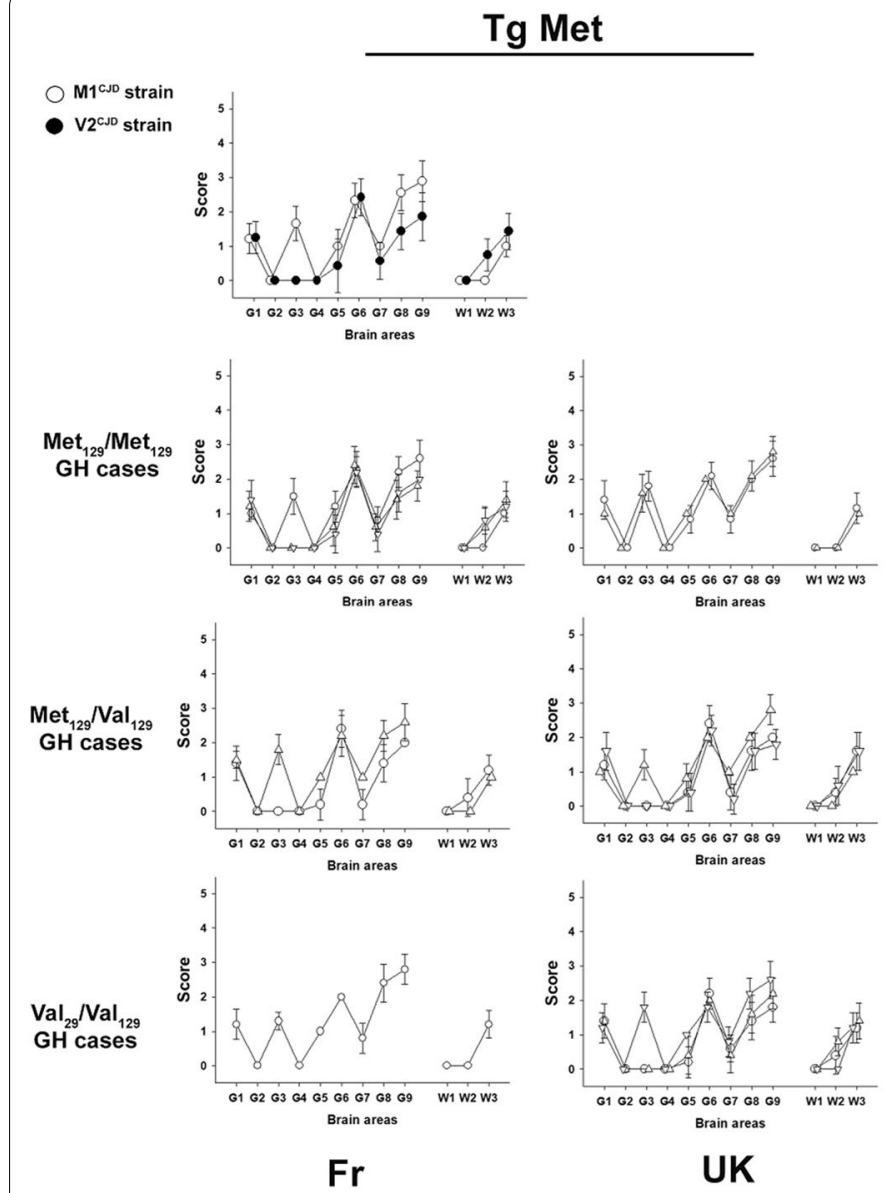

Tg Val
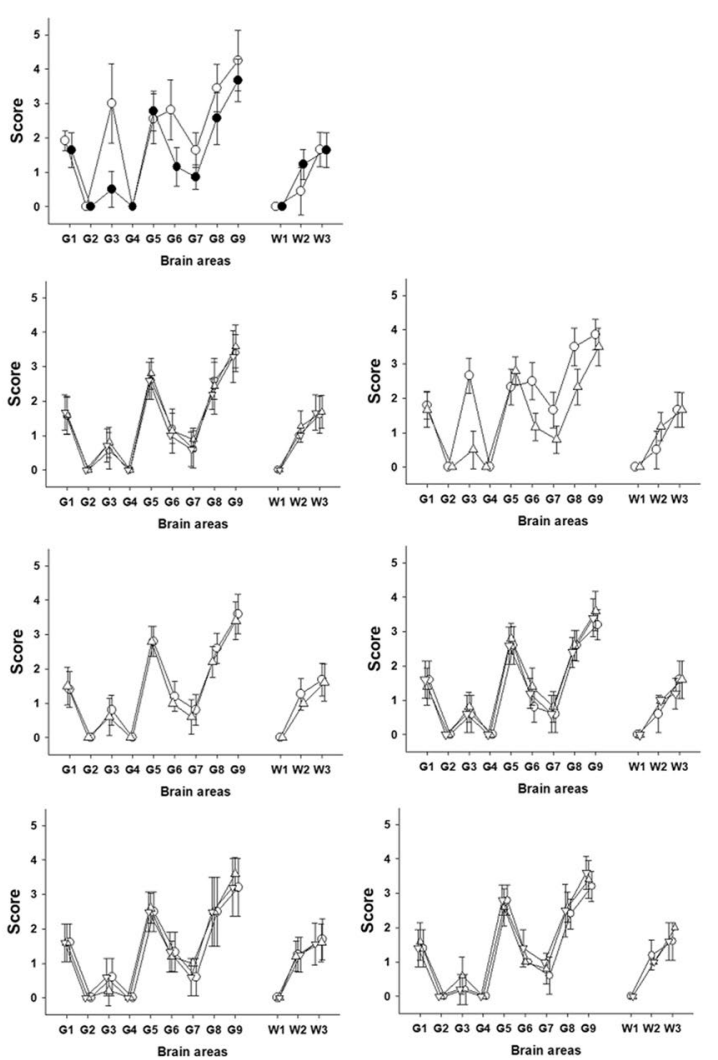

$\mathrm{Fr}$

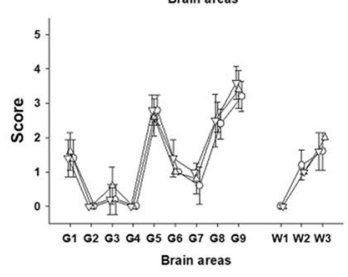

UK

Fig. 3 Vacuolar lesion profiles in the brain of human PrP-expressing mice ( $\mathrm{tgHu}$ ) inoculated with human growth hormone iatrogenic CJD cases originating from France and UK. French (Fr) and UK hGH-iCJD isolates were inoculated in transgenic mice that express Met $_{129}$ (tgMet) or Val ${ }_{129}$ (tgVal) human PrP (intra-cerebral route, 6 mice, 20 $\mathrm{\mu L}$ per mouse). After two iterative passages standardized vacuolar lesion profiles were established in the brains of the mice. Lesion profiles corresponding to $\mathrm{M}^{\mathrm{ID}}(\mathrm{O})$ and $\mathrm{V} 2{ }^{\mathrm{CD}}(\mathbf{O})$ strains are presented for comparison. Results are presented according to the origin (Fr and UK) and the genotype of patients (homozygous Met129: MM—heterozygous Met129/Nal129: MV—homozygous Val129: $\left.V^{\circ}\right)$. Fr MM cases: case $1(\nabla)$, case $2(\Delta)$, case $5(O)$. UK MM: case $6(O)$, case $7(\nabla)$. Fr MV: case $10(O)$, case $12(\Delta)$. UK MV: case 11 : case $9(\nabla)$, cases $9(O)$, case $13(\Delta)$. Fr WV cases: case $18(\Delta)$, case $19(\nabla)$, case $22(O)$. UKV cases: case $14(O)$, case $15(\Delta)$, case $22(\nabla)$. For the Fr WV cases 18 and 19 , second passage in tgMet were not available at the moment of writing (see Table1)

MV2 and VV2 sCJD patients both $\mathrm{M}^{\mathrm{CJD}}$ and $\mathrm{V} 2^{\mathrm{CJD}}$ prions were present as a mixture [11].

Transmission of the 11 French and $11 \mathrm{UK}$ hGH-iCJD cases in mice expressing valine 129 (tgVal) and methionine 129 (tgMet) human PrP variants in this study, represents an unprecedented effort to document the nature of the prion strains responsible for this iatrogenic form of the disease. Our study was primarily designed to test the hypothesis that different prion agents were responsible for the hGH-iCJD outbreaks in France and in the UK. While the design of the experiments was fit for this purpose, the materials (cost and duration of bioassay, availability of material from patients) and ethical considerations limited the number of hGH-iCJD cases that could undergo strain typing by bioassay.

\section{Prion strains in the UK and French hGH-iCJD cases}

The prion strains that were identified in brain isolates prepared from French and UK hGH-iCJD cases following bioassay in $\operatorname{tgHu}$ mice models correspond to prion strains that were previously identified in SCJD patients in France and in the UK using the same mouse models [11].

In contradiction to the initial hypothesis, the prion strains that were identified in the UK and the French GHcases were not radically different. 
In the vast majority of the UK (10 out 11 ) and French (10 out 11 ) cases, the $\mathrm{V}^{\mathrm{CJD}}$ strain or a mixture of $\mathrm{M} 1^{\mathrm{CJD}}+\mathrm{V} 2^{\mathrm{CJD}}$ strains were identified by the strain typing bioassays.

A pure $\mathrm{V} 2{ }^{\mathrm{CJD}}$ strain was observed in all three PRNP genotypes in French hGH-iCJD patients and in two PRNP genotypes ( $\mathrm{MV}$ and VV) in the UK patients. In both countries, $\mathrm{M} 1^{\mathrm{CJD}}+\mathrm{V} 2^{\mathrm{CJD}}$ strain mixtures were identified in the three different PRNP genotypes. A pure $\mathrm{M} 1^{\mathrm{CID}}$ strain was identified in a single UK patient (case 7, MM genotype) and suspected in a French patient (case 22 , VV genotype -definitive transmission results not yet available).

These data strongly support the contention that the difference of epidemiological profile observed between the UK and the French hGH-iCJD outbreaks cannot be attributed to the transmission of different prion strains.

\section{V2 dominant presence is concordant with previous investigations in the UK}

In the UK, several studies have addressed the question surrounding the prion strains responsible for $\mathrm{hGH}-\mathrm{iCJD}$, by the characterisation of the neuropathology features and/or the $\mathrm{PrP}^{\mathrm{res}}$ biochemical properties in the brain of $\mathrm{hGH}-\mathrm{iCJD}$ affected individuals, including those cases investigated by bioassay in this study [22, 24, 33]. So far, no comprehensive description of the neuropathological and biochemical PrPres properties in the French hGH-iCJD cohort is available in the literature.

In a large number of VV and MV UK hGH-iCJD patients, neuropathological features that are considered characteristic of VV2 sCJD cases (including plaque-like deposits) were identified. Along with the biochemical profile of the UK VV and MV hGH-iCJD cases, this leads to the proposal that pituitary glands collected from VV2 sCJD case(s) might have played a preponderant role in the UK $\mathrm{hGH}-\mathrm{iCJD}$ outbreak [22, 24].

The results of this study supports this hypothesis, with the unambiguous identification of the $\mathrm{V} 2^{\mathrm{CJD}}$ strain that was obtained by bioassay of brain homogenate from 6 out of the $9 \mathrm{VV}$ and MV UK hGH-iCJD cases.

Similarly, the identification of MM1-like sCJD neuropathological, biochemical and protein misfolding cyclical amplification (PMCA) features reported in case hGH-iCJD 21 in the earlier study by Ritchie et al. concurs with the pure $\mathrm{M} 1^{\mathrm{CID}}$ strain phenotype we observed in tgHu mice inoculated with cerebral cortex homogenate from the same patient (case 7 in this study). The other UK PRNP codon $129 \mathrm{MM}$ hGH-iCJD case reported by Ritchie et al. (case hGH-iCJD 20) had atypical neuropathological and biochemical features along with PMCA features that suggested the influence of a V2 strain. This case was also included in the present study as case 6, which had transmission characteristics different from case 7 , suggesting a mixed $\mathrm{M} 1^{\mathrm{CID}} / \mathrm{V} 2$ CID strain effect. The transmission findings in cases 6 and 7 therefore provide a direct in vivo correlation that confirms the in vitro findings of Ritchie et al. [24].

\section{Coexistence of several strains in French and UK hGH-iCJD cohorts}

The identification of mixed $\mathrm{M} 1^{\mathrm{CJD}}$ and $\mathrm{V} 2^{\mathrm{CJD}}$ strains in both the UK and the French hGH-iCJD cases raises the question of the origin of this strain diversity.

The pooling of pituitary glands during hGH production from several individuals affected with different strains of SCJD may be one explanation for this phenomenon. However, since the co-existence of $\mathrm{M}^{\mathrm{CJD}}$ and $\mathrm{V} 2^{\mathrm{CJD}}$ strains have been reported in up to $35 \%$ of sCJD cases, the use of pituitary gland from a single donor may also explain the presence of the two strains [7, 11,34].

In France, 12 batches of extracted hGH, all produced between January 1982 and December 1985, were identified as the potential source of infection. According to available data, a batch was in average produced from 1000 to 1500 pituitary glands, meaning that tissue from up to 18000 individuals may have contributed to the atrisk batches [18].

In the UK it is estimated that around 200,000 pituitary glands were used to produce the hGH extracts that were used to treat patients that later developed hGH-iCJD [17].

The SCJD prevalence in industrialized countries is estimated to be approximatively 1.5 cases per million people and per year [35]. In people aged over 50, sCJD frequency significantly increases to reach 5.5 to 7.5 case per million people per year in individuals aged between 65 and 79 [36, 37]. However, in France and in the UK (each with a similar population size), between 600,000 and 700,000 deaths are recorded each year, with $80-130$ sCJD cases diagnosed annually. Based on these figures, the possibility exists that more than one infectious pituitary gland could have entered in the production of the at-risk hGH batches in both France and the UK.

\section{Epidemiological profiles in both countries}

Assuming that the same prion strains are responsible for the UK and French hGH-iCJD cases, the question remains of how the epidemiological differences occurring between the two hGH-iCJD case cohorts may be explained.

The frequency of Met/Met ${ }_{129}, \mathrm{Met}_{\mathrm{Val}} \mathrm{V}_{129}$ and Val/ $\mathrm{Val}_{129}$ individuals in the general population and in their distribution in SCJD cases are similar in France and in the UK [16]. The hGH therapeutic scheme in both countries, including the route of administration (in general intramuscular) and the average age of administration were 
also similar, making these parameters unlikely explanations for the observed epidemiological differences [17$19,23]$.

In experimental TSE models, longer and more widespread incubation periods are classically observed when animals are exposed to decreasing doses of infectivity [38]. The average incubation duration for hGH-iCJD patients from each PRNP codon 129 genotype were significantly longer in the UK patients (VV: 14.3 years-MV: 23.4 years-MM: 30.8 years) when compared with French patients (VV: 9 years-MV: 17.6 years-MM: 12 years) $[16$, 22]. These elements support the hypothesis that French hGH-iCJD affected patients could have been exposed to higher infectious doses than the UK patients.

Although the relevance of findings in experimental TSE models to the physiopathology of CJD in humans is uncertain, they could provide some valuable insights on the relative abilities of SCJD strains to propagate in hosts expressing different human PrP variants.

The end point titrations of $\mathrm{V} 2^{\mathrm{CJD}}$ and $\mathrm{M} 1^{\mathrm{CJD}}$ in tgMet and tgVal indicated that the $\mathrm{M} 1{ }^{\mathrm{CJD}}$ strain displays a 1000-fold lower capacity to propagate in $\mathrm{Val}_{129}$ than in $\mathrm{Met}_{129}$ PrP-expressing host (Additional file 1: Table S1). Conversely, one infectious dose $\left(\mathrm{ID}_{50}\right)$ of $\mathrm{V} 2^{\mathrm{CID}}$ strain (as measured by the intracerebral route in tgVal) transmits with shorter incubation period in tgVal than $10^{7.2} \mathrm{ID}_{50}$ $\mathrm{M} 1^{\mathrm{CJD}}$ strain (as measured by the intracerebral route in tgMet) [11, 32].

When tgHu mice are co-infected with $\mathrm{M} 1^{\mathrm{CJD}}$ and V2 $\mathrm{CJD}$ prions, the nature of the strain(s) that propagate in the brain of the recipients depends on the PRNP genotype at codon 129 and to the specific amount of M1 ${ }^{\mathrm{CJD}}$ and $\mathrm{V} 2^{\mathrm{CJD}}$ infectivity in the inoculum, resulting in the presence of either $\mathrm{M} 1^{\mathrm{CJD}}+\mathrm{V} 2^{\mathrm{CJD}}$ strain mixture or of a pure $\mathrm{M} 1{ }^{\mathrm{CJD}}$ or $\mathrm{V} 2^{\mathrm{CID}}$ strain in the infected host brain (Table 3) [11]. Based on these elements, a scenario where $\mathrm{M} 1{ }^{\mathrm{CJD}}$ and $\mathrm{V} 2^{\mathrm{CJD}}$ would display different abilities to propagate in an individual according to his genotype at codon 129 and the infectious titre of each strain seems plausible. At low infectious doses, as seems possible in the UK hGH situation, the $\mathrm{V} 2^{\mathrm{CJD}}$ strain would dominate, mostly in $\mathrm{VV}$ individuals.

The isolation of a sub-dominant $\mathrm{M} 1^{\mathrm{CJD}}$ strain in homozygous (cases 4 and 5) and heterozygous (case 12) Met $_{129}$ patients indicates that French hGH-iCJD patients were exposed to this prion strain. The transmission of the $\mathrm{M} 1{ }^{\mathrm{CJD}}$ and $\mathrm{V} 2^{\mathrm{CJD}}$ strain in tgMet mice support the view that the $\mathrm{M} 1^{\mathrm{CID}}$ strain, even if present at very low level in the extractive $\mathrm{hGH}$, should propagate as the dominant strain in the homozygous Met $_{129}$ patients. The identification of the $\mathrm{V} 2{ }^{\mathrm{CJD}}$ strain as dominant prion strain in the brain of the homozygous Met $_{129}$ French hGH-iCJD patients is therefore surprising.

These observations could be explained by the effects of a peripheral (non-CNS) route of transmission that would differentially impact on the relative efficiency of $\mathrm{M} 1{ }^{\mathrm{CID}}$ and $\mathrm{V} 2^{\mathrm{CJD}}$ transmission by the intramuscular route of exposure in hGH recipients, resulting in a slow or inefficient transmission of the $\mathrm{M} 1{ }^{\mathrm{CJD}}$ strain.

In a given host, the inoculation by a peripheral route of two prion strains can result in radically different transmission profile, depending on their capacity to replicate early in the lymphoid tissues before neuroinvasion. The inoculation of the HY prion strain in hamsters by the intracerebral, the intraperitoneal or the oral route resulted in all three instances in a highly efficient transmission (100\% attack rate) of the disease. The inoculation of the DY prion strain in hamsters by the intra cerebral route also resulted in a prion disease. In sharp contrast, the inoculation of a high infectious dose of DY prions in hamsters by the intraperitoneal or the oral route failed to transmit the disease [39, 40]. HY but not DY are able to replicate at detectable levels in the lymphoid tissue. Interestingly, $\mathrm{V}^{\mathrm{CJD}}$ strains appeared to replicate at higher levels than $\mathrm{M} 1^{\mathrm{CJD}}$ strain in the lymphoid tissue of tgMet mice [10].

Further investigations will be necessary to confirm the influence of the intramuscular route of infection in modulating $\mathrm{M} 1^{\mathrm{CJD}}$ and $\mathrm{V} 2^{\mathrm{CJD}}$ strain transmission efficiencies. Beyond this, the characterization of the PrP ${ }^{\text {res }}$ and measurement of the infectivity levels in the pituitary glands of SCJD patients and the impact of hGH extraction processes on $\mathrm{M} 1^{\mathrm{CJD}}$ and $\mathrm{V} 2^{\mathrm{CJD}}$ strains from the pituitary glands (removal of infectivity) would be very helpful for appreciating the potential exposure conditions to prions in hGH-treated patients. Ultimately, the direct characterisation of prion infectivity levels and strains in the French and UK hGH-batches that appear to have resulted in the transmission of hGH-iCJD would be very informative.

Although numerous elements are still lacking to fully understand the difference existing between the French and UK hGH-iCJD case cohorts, the results that we report in this study indicate that the nature of the prion strains involved are not fundamental to the observed differences in epidemiological profiles.

Finally, the number of hGH-iCJD cases that we investigated $(n=22)$ should be considered as relatively limited when compared to the total number of hGH-iCJD cases identified in France $(n=122)$ or the UK $(n=81)$. Therefore, we cannot be certain that the panel of hGH-iCJD cases that we investigated necessarily provides a full picture of the prion strain diversity in the French and the UK hGH-iCJD cohorts. 


\section{Abbreviations}

hGH: Human pituitary-derived growth hormone; hDM: Human dura mater iCJD: latrogenic Creutzfeldt-Jakob disease; M $_{129}$ : Methionine at codon 129 of PRNP; tgHu: Human-PrP-expressing transgenic mice; tgMet or tg 340: Homozygous human-PrP-expressing transgenic mice (Methionine 129 variant); tgVal of tg361: Homozygous human-PrP-expressing transgenic mice (Valine 129 variant); sCJD: Sporadic form of Creutzfeldt-Jakob disease; $V_{129}$ : Valine at codon 129 of PRNP; vCJD: Variant Creutzfeldt-Jakob disease.

\section{Supplementary Information}

The online version contains supplementary material available at https://doi. org/10.1186/s40478-021-01247-x.

Additional file 1: Table S1. End point titration of sporadic CJD MM1 and V2 isolates in transgenic mice expressing the human PrP.

\section{Acknowledgements}

We are grateful to Dr Peter Adlard for access to data on the use of hGH in the UK and for helpful discussion, and to Jan Mackenzie for data from the NCJDRSU clinical database. The invaluable work of Dr Mark Head and Helen Yull in the Protein Biochemistry Laboratory and Suzanne Lowrie and Margaret LeGrice in the Neuropathology Laboratory in the NCJDRSU is gratefully acknowledged.

\section{Authors' contribution}

JYD, AH, HC, SL, NA, CM, TB, EC, JLV, KG, VB, Jl and OA conducted the experiments. NS, APL, MBD, EC, Jl and OA provided biological materials for the study. $J Y D, A H, H C, C M, D V, T B, E C, J$ and OA. analysed the data. JYD, AH, HC, CM, $D V, A P L, P P, J P D, E C, M B, D R$, Jl and $O A$ wrote and revised the manuscript. EC, $V B, J$ and $O A$ obtained the funding. All authors read and approved the final manuscript.

\section{Funding}

This work was funded by European Regional Development Fund POCTEFA TRANSPRION (EFA282/13) and REDPRION (EFA148/16), by the UK Food Standards Agency Exploring permeability of the species (M03043 and FS231051), by the European Union through FP7 222887 "Priority", the Alliance Biosecure Foundation (FABS201403) and the French research agency through ANR-15CE18-0028'unmasking blood prions. The National CJD Research \& Surveillance Unit is funded by the United Kingdom's Department of Health Policy Research Program and the Government of Scotland. The views expressed in this publication are those of the authors and not necessarily those of the Department of Health or the Government of Scotland. The Edinburgh Brain Bank is supported by the Medical Research Council.

\section{Competing interests}

The authors declare that they have no competing interests.

\section{Author details}

1 UMR INRAE ENVT 1225, Interactions Hôtes-Agents Pathogènes, École Nationale Vétérinaire de Toulouse, 23 Chemin des Capelles, 31076 Toulouse, France. ${ }^{2}$ BIORAN Team, Lyon Neuroscience Research Center, CNRS UMR 5292 - INSERM U1028, Université de Lyon - Université Claude Bernard, Lyon, France. ${ }^{3}$ Neurochemistry Laboratory, Biochemistry Department, Centre de Pathologie et Neuropathologie Est, Hospices Civils de Lyon, Bron, France. ${ }^{4}$ Laboratoire Universitaire d'Anatomie Pathologique, INSERM U 1214 TONIC, CHU Purpan, C.H.U. Rangueil - 1 Avenue Jean Poulhès, 50032 - 31059 Toulouse Cedex9, TSA, France. ${ }^{5}$ CEA, Service d'Etude des Prions et des Infections Atypiques, Université Paris-Saclay, 18 Route du Panorama, 92265 Fontenay-aux-Roses, France. ${ }^{6}$ INRAE, AgroParistech, GABI, Université Paris-Saclay, Jouy-en-Josas, France. ${ }^{7}$ INRAE, UVSQ, VIM, Université Paris-Saclay, 78350 Jouy-en-Josas, France. ${ }^{8}$ National Creutzfeldt-Jakob Disease Research and Surveillance Unit, Centre for Clinical Brain Sciences, Western General Hospital, University of Edinburgh, Edinburgh $\mathrm{EH} 4$ 2XU, UK.

Received: 12 July 2021 Accepted: 18 August 2021

Published online: 28 August 2021

\section{References}

1. McKinley MP, Bolton DC, Prusiner SB (1983) A protease-resistant protein is a structural component of the scrapie prion. Cell 35(1):57-62

2. Prusiner SB (1998) Prions. Proc Natl Acad Sci USA 95(23):13363-13383

3. Fraser H, Dickinson AG (1973) Scrapie in mice. Agent-strain differences in the distribution and intensity of grey matter vacuolation. J Comp Pathol 83(1):29-40

4. Zerr I, Parchi P (2018) Sporadic Creutzfeldt-Jakob disease. Handb Clin Neurol 153:155-174. https://doi.org/10.1016/B978-0-444-63945-5. 00009-X

5. Parchi P, Castellani R, Capellari S et al (1996) Molecular basis of phenotypic variability in sporadic Creutzfeldt-Jakob disease. Ann Neurol 39(6):767-778

6. Puoti G, Giaccone G, Rossi G, Canciani B, Bugiani O, Tagliavini F (1999) Sporadic Creutzfeldt-Jakob disease: co-occurrence of different types of $\operatorname{PrP}(\mathrm{Sc})$ in the same brain. Neurology 53(9):2173-2176

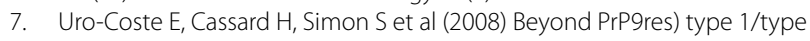
2 dichotomy in Creutzfeldt-Jakob disease. PLoS Pathog 4(3):e1000029. https://doi.org/10.1371/journal.ppat.1000029

8. Bishop MT, Will RG, Manson JC (2010) Defining sporadic CreutzfeldtJakob disease strains and their transmission properties. Research support, non-U.S. Gov't. Proc Natl Acad Sci USA 107(26):12005-12010. https://doi. org/10.1073/pnas.1004688107

9. Cassard H, Torres JM, Lacroux C et al (2014) Evidence for zoonotic potential of ovine scrapie prions. Nat Commun 5:5821. https://doi.org/10.1038/ ncomms6821

10. Jaumain E, Quadrio I, Herzog L et al (2016) Absence of evidence for a causal link between bovine spongiform encephalopathy strain variant L-BSE and known forms of sporadic Creutzfeldt-Jakob disease in human PrP transgenic mice. J Virol 90(23):10867-10874. https://doi.org/10.1128/ JVI.01383-16

11. Cassard H, Huor A, Espinosa JC et al (2020) Prions from sporadic Creutzfeldt-Jakob disease patients propagate as strain mixtures. MBio. https://doi.org/10.1128/mBio.00393-20

12. Chapuis J, Moudjou M, Reine F et al (2016) Emergence of two prion subtypes in ovine PrP transgenic mice infected with human MM2-cortical Creutzfeldt-Jakob disease prions. Acta Neuropathol Commun 4:10. https://doi.org/10.1186/s40478-016-0284-9

13. Kobayashi A, Sakuma N, Matsuura Y, Mohri S, Aguzzi A, Kitamoto T (2010) Experimental verification of a traceback phenomenon in prion infection. J Virol 84(7):3230-3238. https://doi.org/10.1128/JVI.02387-09

14. Douet JY, Huor A, Cassard H et al (2021) Wide distribution of prion infectivity in the peripheral tissues of VCJD and SCJD patients. Acta Neuropathol 141(3):383-397. https://doi.org/10.1007/s00401-021-02270-x

15. Duffy P, Wolf J, Collins G, DeVoe AG, Streeten B, Cowen D (1974) Letter: possible person-to-person transmission of Creutzfeldt-Jakob disease. N Engl J Med 290(12):692-693

16. Brown P, Brandel JP, Sato T et al (2012) latrogenic Creutzfeldt-Jakob disease, final assessment. Emerg Infect Dis 18(6):901-907. https://doi.org/ 10.3201/eid1806.120116

17. Swerdlow AJ, Higgins CD, Adlard P, Jones ME, Preece MA (2003) Creutzfeldt-Jakob disease in United Kingdom patients treated with human pituitary growth hormone. Neurology 61(6):783-791. https://doi. org/10.1212/01.wnl.0000084000.27403.15

18. Peckeu L, Brandel JP, Welaratne A, Amar E, Costagliola D, Haik S (2020) Factors influencing the incubation of an infectious form of CreutzfeldtJakob disease. Clin Infect Dis 70(7):1487-1490. https://doi.org/10.1093/ cid/ciz692

19. Peckeu L, Brandel JP, Welaratne A, Costagliola D, Haik S (2018) Susceptibility to Creutzfeldt-Jakob disease after human growth hormone treatment in France. Neurology 91(8):e724-e731. https://doi.org/10.1212/WNL. 0000000000006028

20. Palmer MS, Dryden AJ, Hughes JT, Collinge J (1991) Homozygous prion protein genotype predisposes to sporadic Creutzfeldt-Jakob disease. Nature 352(6333):340-342

21. Brown P, Brandel JP, Preece M, Sato T (2006) latrogenic Creutzfeldt-Jakob disease: the waning of an era. Neurology 67(3):389-393 
22. Rudge $P$, Jaunmuktane $Z$, Adlard $P$ et al (2015) latrogenic CJD due to pituitary-derived growth hormone with genetically determined incubation times of up to 40 years. Brain 138(Pt 11):3386-3399. https://doi.org/ 10.1093/brain/awv235

23. Brandel JP, Preece M, Brown P et al (2003) Distribution of codon 129 genotype in human growth hormone-treated CJD patients in France and the UK. Lancet 362(9378):128-130. https://doi.org/10.1016/S01406736(03)13867-6

24. Ritchie DL, Barria MA, Peden AH et al (2017) UK latrogenic CreutzfeldtJakob disease: investigating human prion transmission across genotypic barriers using human tissue-based and molecular approaches. Acta Neuropathol 133(4):579-595. https://doi.org/10.1007/s00401-016-1638-x

25. Moreno CR, Moazami-Goudarzi K, Laurent P et al (2007) Which PrP haplotypes in a French sheep population are the most susceptible to atypical scrapie? Arch Virol 152(6):1229-1232

26. Andreoletti O, Levavasseur E, Uro-Coste E et al (2002) Astrocytes accumulate 4-hydroxynonenal adducts in murine scrapie and human Creutzfeldt-Jakob disease. Neurobiol Dis 11(3):386-393

27. Padilla D, Beringue V, Espinosa JC et al (2011) Sheep and goat BSE propagate more efficiently than cattle BSE in human PrP transgenic mice. PLoS Pathog 7(3):e1001319

28. Outram GW (1976) The pathogenesis of scrapie in mice. Front Biol 44:325-357

29. Lacroux C, Comoy E, Moudjou M et al (2014) Preclinical detection of variant CJD and BSE prions in blood. PLoS Pathog 10(6):e1004202. https:// doi.org/10.1371/journal.ppat.1004202

30. Feraudet C, Morel N, Simon S et al (2005) Screening of 145 anti-PrP monoclonal antibodies for their capacity to inhibit PrPSc replication in infected cells. J Biol Chem 280(12):11247-11258. https://doi.org/10.1074/ jbc.M407006200

31. Fraser H, Dickinson AG (1968) The sequential development of the brain lesion of scrapie in three strains of mice. J Comp Pathol 78(3):301-311

32. Huor A, Douet JY, Lacroux C et al (2017) Infectivity in bone marrow from sporadic CJD patients. J Pathol 243(3):273-278. https://doi.org/10.1002/ path.4954
33. Jansen C, Parchi P, Capellari S et al (2012) Human prion diseases in the Netherlands (1998-2009): clinical, genetic and molecular aspects. PLoS ONE 7(4):e36333. https://doi.org/10.1371/journal.pone.0036333

34. Polymenidou M, Stoeck K, Glatzel M, Vey M, Bellon A, Aguzzi A (2005) Coexistence of multiple PrPSc types in individuals with Creutzfeldt-Jakob disease. Lancet Neurol 4(12):805-814

35. Ladogana A, Puopolo M, Croes EA et al (2005) Mortality from CreutzfeldtJakob disease and related disorders in Europe, Australia, and Canada. Neurology 64(9):1586-1591

36. Nishimura Y, Harada K, Koyama T, Hagiya H, Otsuka F (2020) A nationwide trend analysis in the incidence and mortality of Creutzfeldt-Jakob disease in Japan between 2005 and 2014. Sci Rep 10(1):15509. https://doi.org/10. 1038/s41598-020-72519-0

37. Sun Y, Liu CC, Fan LY et al (2020) Incidence of and mortality due to human prion diseases in Taiwan: a prospective 20-year Nationwide Surveillance Study from 1998 to 2017. Clin Epidemiol 12:1073-1081. https://doi.org/ 10.2147/CLEP.S274093

38. Arnold ME, Hawkins SA, Green R, Dexter I, Wells GA (2009) Pathogenesis of experimental bovine spongiform encephalopathy (BSE): estimation of tissue infectivity according to incubation period. Vet Res 40(1):8

39. Bartz JC, Dejoia C, Tucker T, Kincaid AE, Bessen RA (2005) Extraneural prion neuroinvasion without lymphoreticular system infection. Comparative study research support, N.I.H., extramural research support, U.S. Gov't, non-P.H.S. research support, U.S. Gov't, P.H.S. J Virol 79(18):11858-11863. https://doi.org/10.1128/JVI.79.18.11858-11863.2005

40. Bessen RA, Martinka S, Kelly J, Gonzalez D (2009) Role of the lymphoreticular system in prion neuroinvasion from the oral and nasal mucosa. J Virol 83(13):6435-6445. https://doi.org/10.1128/JVI.00018-09

\section{Publisher's Note}

Springer Nature remains neutral with regard to jurisdictional claims in published maps and institutional affiliations.
Ready to submit your research? Choose BMC and benefit from:

- fast, convenient online submission

- thorough peer review by experienced researchers in your field

- rapid publication on acceptance

- support for research data, including large and complex data types

- gold Open Access which fosters wider collaboration and increased citations

- maximum visibility for your research: over 100M website views per year

At BMC, research is always in progress.

Learn more biomedcentral.com/submissions 